WILLIAM F. MURPHY, PH.D.

\title{
EXPOSING SEXUAL PREDATORS WHO RUN MARTIAL ARTS SCHOOLS $^{1}$
}

I love my sports heroes and my sports, but I hate sex offenders using sports to come in contact with vulnerable people even more. -William F. Murphy

William Murphy, a college professor and a black belt in the Brazilian Jiu-Jitsu community, frowned as he considered a project that he had been working on. Working in conjunction with Georgette Oden, a lawyer and the head of investigations at Bullshido.net, he had proposed a systematic investigation that would seek to identify sex offenders within the martial arts instruction community. Now he needed to figure out just how far he was willing to go in that investigation.

The context of the project involved many different elements. First, there was the broad mixed martial arts community, which consisted of many different sub-communities that focused on different fighting styles. Each of these communities had their own network of schools that taught the style's techniques. Also involved was the Bullshido.net community, a controversial website whose original purpose was to investigate fraud, abuse, and "BS" within the martial arts community. While this group could be mobilized to crowdsource investigations, its membership tended to be highly opinionated and more than occasionally crude. Any results provided by such a group would therefore require considerable scrutiny. Finally, there was the potential application of cyber forensics. This would involve the systematic acquisition of data from different online sources and the matching of these sources to identify — for example-individuals who were both martial arts instructors and registered on sex-offender databases.

Murphy recognized that the project was fraught with challenges. As was often the case when working with different databases, data sources were often incomplete and also needed considerable cleaning before they would be useful. Matching records was also a potential challenge. Names were often written in different ways and common names could easily lead to erroneous matches. Crowdsourcing the potential verification of matches depended heavily on the degree to which participants in the process were willing to be objective and did not have any potential hidden agendas. This type of investigation also had major potential legal implications, as well as privacy concerns.

Weighed against these drawbacks were the potential victims that might be spared if instructors with a history of sex offenses could be identified and removed from schools where they had access to unwitting - and often under-aged victims. The project had been initiated by Oden as a result of identifying one such individual. How many more might there be?

\footnotetext{
${ }^{1}$ Copyright (C 2018, William F. Murphy, Ph.D. This case was prepared for the purpose of class discussion, and not to illustrate the effective or ineffective handling of an administrative situation. Names and some information have been disguised. This case is published under a Creative Commons BY-NC license. Permission is granted to copy and distribute this case for non-commercial purposes, in both printed and electronic formats
} 


\section{Cyber Forensics}

Murphy's proposed investigation fell under a domain loosely referred to as computer forensics or cyber forensics. The U.S. Computer Readiness Team, a unit within the government's Department of Homeland Security, characterized the term as follows (US-CERT, 2008, p. 1):

Forensics is the process of using scientific knowledge for collecting, analyzing, and presenting evidence to the courts. (The word forensics means "to bring to the court.") Forensics deals primarily with the recovery and analysis of latent evidence. Latent evidence can take many forms: from fingerprints left on a window, to DNA evidence recovered from blood stains, to the files on a hard drive.

Because computer forensics is a new discipline, there is little standardization and consistency across the courts and industry. As a result, it is not yet recognized as a formal "scientific" discipline. We define computer forensics as the discipline that combines elements of law and computer science to collect and analyze data from computer systems, networks, wireless communications, and storage devices in a way that is admissible as evidence in a court of law.

There were two key elements to the cyber forensic process. First, the sources of data must be identified and, in many cases, linkages between different sources established. The data involved in a cyber forensic investigation could come from many sources:

- Persistent data, examples of which included:

o Standard databases, both local and online

$0 \quad$ Files and collections of files

o Offline data, such as written records (which extends the domain to more conventional forensics)

- Volatile data, which must be captured and recorded. Examples included:

o Contents of a computer's RAM at a point of time

o Network traffic

o Frames from a streaming video

- Discarded or corrupted data, generally a subset of persistent data that included:

o Residue from deleted files

o Data that could be acquired from damaged media

Whatever the source of the data used in a cyber forensic investigation, the second key element of the process was ensuring (and demonstrating) that it had not been tainted in a manner that would make it inadmissible as evidence in court. There were many ways that evidence could acquire such a taint. Just a few of these included:

- Failure to maintain a chain of custody, meaning that the security of the data had not been tracked from its time of acquisition until it reached the courtroom. Without such a chain, a lawyer could open up the possibility that the evidence might have been subject to tampering.

- Data that was acquired illegally, for example recordings from an illegal wiretap or from breaking into an office without a warrant.

- Data that was damaged in the course of acquiring it. For example, it was easy to corrupt volatile data in the process of capturing it, particularly for inexperienced investigators. 
For these reasons, cyber forensic investigators needed access to both high levels of technical expertise and legal/law enforcement expertise if they were to build an effective case.

\section{The Jiu-Jitsu and MMA Community}

In the early 1990's a Brazilian named Royce Gracie shocked the world by defeating opponent after opponent in a no rules fighting prize fight event called the Ultimate Fighting Championship, despite being the lightest man in the brackets. Mr. Gracie beat professional boxers, he beat Olympic grade wrestlers, he beat kickboxers, he beat champion Judo players, and he beat Karate fighters, and even Sumo wrestlers. Mr. Gracie practiced Jiu-Jitsu in the Gracie style, which meant clinching an opponent, taking them to the ground (whether or not that meant being in a bottom position or a top position) and then choking the opponent out with his arms or his legs, or alternatively using two of his own limbs to apply destructive pressure to one of his opponent's joints until his opponent either tapped out or their limb broke (Gracie Jiu-Jitsu Academy, n.d.).

Mr. Gracie's unbeaten success in the next few no rules tournaments caused a revolution within the martial arts community of interest in both Mixed Martial Arts rules competitions, validated the effectiveness of grappling techniques as martial arts, and spawned a billion-dollar industry (“The UFC,” n.d.).

It also produced a rather strange community of Jiu-Jitsu practitioners that emphasized real fighting challenge matches, and a loyalty to the Jiu-Jitsu community. Within the Jiu-Jitsu community, there was often a mindshare war between those that felt that might makes right and individual liberties based on one's ability to back one's self up, versus those in the Jiu-Jitsu community that believed that Jiu-Jitsu had to foster moral development, and not just the ability to effectively fight, within its practitioners (Murphy, 2015). This was unsurprising as the effectiveness of Jiu-Jitsu techniques in "street" situations made it widely adopted by law enforcement, the military, surf gangs, drug using groups, health-minded groups who opposed alcohol/drug/tobacco/junk food use, and also by the various other combat sport practitioners. The one common thread to all these groups was that Jiu-Jitsu gave the individuals who practiced it the ability to take people down, choke them, and joint lock them, and surrounded them with a large group of other people who had similar abilities, and a sense of loyalty to their own Jiu-Jitsu group.

\section{Origins}

Every geographic culture has some form of wrestling. In Japan, one of the forms of wrestling called JiuJitsu, included chokes, throws, strikes, and joint locks, and formed the precursor art to what has become the Olympic sport of Judo. In Brazil, several groups, most famously the Gracie family, resisted what they called the sportification of Jiu-Jitsu, retaining the practice of several techniques considered dirty tactics or poor play in the sport of Judo. The Gracie's argued that what a sport considered dirty tactics were actually often the exact tactics that were the most effective in real, no rules fights. Jiu-Jitsu was traditionally practiced in a Japanese Judo uniform called a Gi, but there have been submission grappling traditions throughout history that were practiced with jackets or with minimal uniforms that utilize similar throws, chokes, joint locks, and positional pinning strategies (Gracie Jiu-Jitsu Academy, n.d.).

\section{Why Did People Engage in Jiu-Jitsu and Mixed Martial Arts Training?}

There were ongoing discussions within different factions of the Jiu-Jitsu community whether the ultimate purpose of Jiu-Jitsu training was self-defense, or to prepare for no rules fighting situations, or as a form of submission wrestling. 
Self-defense was usually thought to include training to avoid situations where one may come to harm, and to survive such situations with minimal harm when they could not be avoided. These situations may be called "street fights," "assault and batteries," "rape attempts,” or “robbery attempts”.

No rules fighting, also called Vale Tudo, no holds barred fighting, and Mixed Martial Arts (MMA) usually referred to competitions where two opponents may utilize striking techniques, throwing/takedown techniques, groundwork such as pinning positions, chokeholds, and joint locks to either knock their opponent out, or to get their opponent to signal submission. The Ultimate Fighting Championship (UFC) was a well-known MMA tournament operation.

Submission Wrestling was like MMA without the strikes. It was where two opponents used throws, takedowns, ground positional techniques such as pins, choke holds, and joint locks to render their opponent unconscious or signal submission (or in some rule sets to score points).

Moral development had always been held as a component of combat sport and martial arts training by a large percentage of practitioners throughout history. However, a certain percentage of combat sport practitioners rejected this idea and said that training for hand to hand combat effectiveness was separate from moral training, and that one had nothing to do with the other.

There had been many martial arts organizations, and Jiu-Jitsu was no exception, that had been accused of having cult like practices, and demanding cult like obedience and adherence to approved party lines of thinking, acting, and speaking. There were also widespread reports of people being socially (or even physically) punished for switching Jiu-Jitsu teams.

\section{Jiu-Jitsu and Mixed Martial Arts was a Billion Dollar Business}

Brazilian Jiu-Jitsu was a price premium activity, where members usually paid between $\$ 75$ to $\$ 300$ a month for training, between $\$ 50$ to $\$ 200$ for each uniform, and between $\$ 50$ to $\$ 100$ to enter tournaments as amateurs.

Network affiliation fees, promotion fees, instructional content product sales, and merchandise sales all represented large revenue streams for the incumbent stakeholders within the Jiu-Jitsu and MMA communities.

\section{Jiu-Jitsu \& Mixed Martial Arts Training was a Largely Unregulated Activity}

The teaching of martial arts was a loosely regulated, and largely unregulated activity, with a high degree of immigrant participation as business owners and instructors.

Whereas in many states, one had to go through a careful licensure and vet process to open a daycare, it seemed that in many states, that requirement did not exist to open an after school martial arts program.

In other words, one could say they were a martial arts teacher, open a martial arts school, and pick up other people's children from school--keeping those children for several hours a day in exchange for lucrative fees--all without a required vetting process in many states.

\section{Bullshido.Net}

Both the potential of martial arts instruction to engender cult-like adherence and their largely unregulated nature made martial arts schools, and the martial arts in general, vulnerable to predatory behaviors. Bullshido.net was a website that was originally formed to report, discuss, and investigate fraud, abuse, and "BS" in the martial arts. It was not a site without controversy, as their posters often made blunt, 
sarcastic, vulgar, and insulting posts regarding investigation subjects and each other. The site was also frequently accused of being biased towards martial arts that had sporting aspects and had proven track records in Mixed Martial Arts competitions.

\section{Bullshido Membership}

Bullshido members and investigators came from across martial art disciplines, across professional backgrounds, and across educational backgrounds. Its members came from many different countries, with postings forming an international and multi-cultural collective of knowledge. Broadly speaking, Bullshido could be described as a volunteer, crowd sourced knowledge repository, discussing topics that were highly relevant to the martial arts and combat sports community (Bullshido, n.d.). The membership distribution of the Bullshido community by country, occupation and education is presented in Exhibit 1.

Bullshido.net was an open access website, meaning that it did not charge anyone to read its content, and members could post with either free or paid memberships. Paying for memberships or making donations was voluntary, but provided niceties such as having a profile picture and being able to include business or personal URLs with the individual's posts.

\section{Bullshido as an Informing System}

Conceptually, the Bullshido.net site could also be described as the channel within a broader informing system. Within the informing science transdiscipline, informing systems tended to emerge where four conditions existed (Gill and Bhattacherjee, 2009):

- $\quad$ The client has an unaddressed set of problems ( $p .41)$

- $\quad$ Serving the client provides access to resources (p. 41)

- $\quad$ The members of the discipline have the expertise to address the client's unaddressed problem ( $p$. 42)

- $\quad$ One or more resonant communications channels exist, or can be created (p. 42)

The Bullshido community, for which the Bullshido.net website served as a channel, had a variety of characteristics that were congruent with the constructs found in the informing science model:

- Bullshido.net posters were senders of public messages, sharing their knowledge and findings with other Bullshido.net members, readers, and the world.

- Bullshido.net staff members maintained forum rules and mentored new members who were posting (often in a rather brusque way).

- Bullshido.net paid members and staff constantly reshaped and redefined the Bullshido.net informing environment, through the creation of new forums, cleaning up of topic lines of communication into more appropriate forum threads, and revising the rules of conduct on the site for posting as necessary.

- Bullshido.net provided several communication channels including the forums, published web articles, its own Facebook page, and co-publishing relationships with the various news outlets related to Jiu-Jitsu and Mixed Martial Arts. 
- Bullshido informing system clients included Bullshido.net investigators, Bullshido.net members, and Bullshido.net "lurkers" (those who read the threads, but did not post and/or had not set up accounts, and other Jiu-Jitsu and Mixed Martial Arts news websites and social media outlets).

"In order to serve these clients effectively, the research being communicated must meet three criteria: rigor, relevance, and resonance" (Murphy, 2011).

In order for Bullshido to serve as an effective informing system, it needed to provide information that was rigorous, relevant, and that was communicated to its clients through channels that resonated with those clients.

Rigor: Bullshido.net attempted to achieve rigor with a ruthless public peer feedback model. Posters who posted incorrect, dubious, or off topic posts were bluntly (and often profanely) called out by other posters, including experts and staff members for making bad posts. There was also an "upvote" and "downvote" system, through which all posts could get rated for all the world to see by the crowdsourced Bullshido.net members. Recognized and confirmed subject matter experts were often given heavy weight for their posts in their areas of expertise, but even subject matter experts were called out when they made bad or questionable posts. In fact, it was a commonly enforced custom on Bullshido.net that all claims made must be proven when challenged. A common saying on Bullshido.net regarding one's accomplishments was: "Provide a video or it did not happen.”

Relevance: Relevance of posts was achieved in three different ways. First, the members of the site tended to have a universally held interest in combat sports, martial arts, or combat related domains, such as firearms and shooting. Second, posters who made off topic or uninteresting posts were ruthlessly lambasted by other member posters. Third, Bullshido.net staff members moved irrelevant posts to more relevant forums or to a catch all forum called "Trollshido".

Resonance: Resonance referred to the ability of a message to pass through a particular communication channel and to make it through the various barriers imposed by that channel as well as being acceptable to the existing mental model held by the client without being lost or distorted. Bullshido.net sought to achieve resonance by providing communication forums that had daily engagement by posters, and by maintaining multiple channels including the forums, the Bullshido Facebook page, and various co-publishing relationships with the external social media and news outlets that also served in the Jiu-Jitsu and Mixed Martial Arts community.

\section{Project Background}

The project to identify sex offenders in the martial arts instruction community in large part evolved as a result of the efforts of two key individuals: Georgette Oden and William Murphy. Both came to the project as active participants within the Brazilian Jiu-Jitsu community.

\section{Georgette Oden, J.D.}

Georgette Oden was no stranger to fighting. She was a lawyer, trained in logic and debate. She was a competitor in Brazilian Jiu-Jitsu, where she had earned the rank of purple belt before needing to take a break for medical reasons, surviving breast cancer and a mastectomy. She was also a rape survivor. Finally, she was the head of BJJ investigations at Bullshido.com, a controversial website whose original purpose was to investigate fraud, abuse, and "BS" within the martial arts community. 
The project originated when Oden had discovered that Paul Saucido (a brown belt instructor within the Jiu-Jitsu community) had confessed to raping an unconscious woman, resulting in his being convicted of a sex offense crime which required him to register as a sex offender. She had also discovered that at some point after his conviction, he claimed to have been promoted to the rank of black belt by an extremely high ranking and well-known member of the Jiu-Jitsu community, and worse, he had opened a new martial arts school and was teaching self-defense classes to the public again.

Oden suspected that many of Saucido's students probably were not aware of his sex offender status. What's more, she knew that the instructor from whom Saucido had claimed to have achieved black belt status had promised to sever all ties with Saucido after Saucido confessed to raping the unconscious woman.

There was a mystery here, and a failure of caveat emptor. Oden could imagine parents unsuspectingly dropping off their sons and daughters at Saucido's school for hands on grappling and self-defense instruction, and she decided right then and there to get to the bottom of who promoted Paul Saucido to black belt (if anybody) and to make sure that the Jiu-Jitsu community knew that he was a convicted sex offender.

\section{William F. Murphy, Ph.D.}

Bill Murphy was a high ranking black belt in the Brazilian Jiu-Jitsu community. He was already somewhat controversial in this community because he had launched an awareness campaign to criticize a practice allowed by some tournaments and coaches. That practice involved for profit tournaments charging admission for spectators to watch children under the age of 12 to choke each other or apply joint locks on each other without mandatory early referee stoppage once a submission hold was locked in on the other child. Because of that awareness campaign, Murphy had received a number of death threats from people whose very business was the practice and teaching of how to effectively apply violence onto other people.

Now, Murphy was thinking about participating in another awareness campaign, and this one would probably result in similar resentments towards his person by members of his own Jiu-Jitsu community that thought that running these awareness campaigns was bad for their businesses.

This new awareness campaign was an extension of the investigation and discussion involving Paul Saucido, led by Oden, that Murphy had participated in on Bullshido.net. That investigation had particular relevance to Murphy because the individual that had allegedly promoted Saucido to black belt was Rigan Machado. Rigan was a living legend in the Jiu-Jitsu community, having been a fighter and competitor in the 1980's through the early 2000's, going head to head with and often beating some of the best grapplers on the planet. Murphy had often competed against the Machado's teams in the 1990's, and he had great respect for them. In fact, he considered Machado to be one of his early sports heroes.

Murphy had to assess if his participation in the investigation would make it more fair or less fair given his ties to the Jiu-Jitsu community and his own high black belt ranking. And he also had to consider what type of negative feedback he was prepared to endure from the Jiu-Jitsu community, of which he was a high-ranking member, for participating in yet another consumer protection campaign with a demographic that was very outspoken, was well trained in violence, and who did not like to be told what to do by anybody. 


\section{The Investigation Value of Public Social Media Sites}

"Online Social Networks (OSN) have become the largest and fastest growing websites on the Internet... and contain the sensitive and personal data of hundreds of millions of people” (Huber, Mulazzani, Leithner, Schrittwieser, Wondracek \& Weippi, 2011, p. 113). The key to the first investigation and the key to the second investigation was the ability to pull incriminating evidence from publicly available social media sites, where the subjects under investigation had willingly left public evidence trails. Investigation shops, whether they be private, non-profit advocacy groups, or law enforcement had all found that both public or private social media content had a significant value as evidence sources to investigators. "Capturing evidence from social media sites can significantly support the evidence gathered from other sources” (Sans Institute, 2014, p. 2).

The use of social media evidence by investigators had only been growing. "Recently, academia and law enforcement alike have shown a strong demand for data that is collected from online social networks" (Huber et al., 2011, p. 113).

"Collecting and presenting digital evidence to support an administrative investigation can make or break the case against the accused" (Sans Institute, 2014, p. 1). However, one of the lessons learned from the first investigation was that when the coaches in the Machados network and Paul Saucido became aware that they were being investigated, much of the web evidence and social media evidence disappeared (presumably pulled down by the account owners who posted it). "Social media content, is by its nature, volatile (e.g., the originator can sometimes delete or modify a previously posted element)” (Sans Institute, 2014, p. 14).

But the key to success with such an investigation was that the subjects of the investigation not become prematurely aware that they were being investigated, or all of the evidence will "disappear". Murphy commented:

And that was exactly what happened after the investigation into Paul Saucido was made public; almost all of the social media evidence concerning Paul Saucido teaching after his conviction as a registered sex offender was pulled down from across the Rigan Machado network of black belts as well as Paul Saucido's own social media and web presences. Luckily the Bullshido members working on this investigation had made copies of the incriminating evidence they already had, but this made it much more difficult to investigate the remaining loose ends regarding Paul Saucido's return to teaching the general public self-defense and being promoted to a black belt after his sex offender conviction.

Prior to the evidence being pulled down, Bullshido members (in a crowd sourced fashion) had combed over his public Facebook pages, and the public Facebook pages on the Rigan Machado network of blackbelts, their public websites, and their public twitter feeds to gather evidence trails to document that Paul Saucido had returned to teaching self-defense to the general public, that he was seen at his own school and Rigan Machado's school wearing his black belt, and the claims he had made regarding his post-conviction promotion to black belt and coaching activities.

Ultimately, the investigation of Saucido led to a posting on the Bullshido website, as shown in Exhibit 2.

\section{The Proposed Extended Investigation}

After the Paul Saucido investigation, Murphy reached out to Oden with an idea that he had. While he thought that catching and exposing the sex offenders in coaching roles on a one at a time basis was good, 
he thought that it might be even more valuable to try and check the sex offender status of every publicly listed black belt and coach in Brazilian Jiu-Jitsu that they could, using the publicly available data.

\section{Data Sources}

So, Murphy compiled the list of coaches and black belts on record with the largest tournament organizations, and the largest Brazilian Jiu-Jitsu organizations (who often published such lists as a marketing courtesy to the participating coaches, school owners, and black belts), and began running them through the sex offender registry.

\section{Protocol}

Murphy came up with the following initial protocol. It was imperative that some level of secrecy during the investigation be maintained until it was completed, as the Paul Saucido investigation resulted in Saucido and the other black belts pulling down all evidence of their activities with Saucido from their websites and social media feeds.

First, Murphy recruited two ex-career cops, both of whom went into teaching at universities full-time after their retirement from Law Enforcement. One was a Criminal Justice Professor, and the other was a Cyber Forensics Professor and they both agreed to provide investigation guidance. Murphy also recruited a professional sports journalist who worked full-time for traditional print newspapers to provide journalistic guidance. Finally, Murphy recruited a small team of volunteers who each committed to spending 9 hours a week running the following protocol, should Murphy and Oden make the decision to proceed with the project:

1. They would take the names from the list of coaches and black belts and run them through the sex offender registry to determine if there were any matches.

2. When there a match (or matches) between a coach's name and the sex offender registry was found, Murphy and his team would pull the picture on file from the National Sex Offender Registry and the picture from the arrest mug shot (where available).

3. The photos obtained would then be compared to the pictures of the coach/black belt on their martial arts school website and school Facebook page to cross validate and to rule out false positives.

4. A Word doc, complete with the National Sex Offender Registry information and pictures, and the school instructor pictures would then be compiled. Each positive hit would be cross validated by at least three different people to rule out false positives prior to publication.

Murphy also asked Oden, in her capacity as a lawyer, to research the state level restrictions that registered sex offenders must abide by in certain key states: California, NY, Florida and Texas. They would then make a note if any of these offenders appeared to be either in violation of their parole, or in violation of state/national restrictions on registered sex offenders.

In the event the project moved forward, Murphy and his team would write up the summary of the findings. The goal would be to publish three different documents:

1) A Research Case Report that presents the need for the project, the research methods of the project, and the results of the project. This report would be:

- Submitted to Law Enforcement in the locale of any parole or restriction violators to facilitate arrests and make them aware of this type of problem. 
- Submitted to an academic Cyber Forensics journal for publication.

- Used as the basis of a summary to be submitted to Bullshido.net and Murphy's blog site. It would further be disseminated to the various BJJ and MMA related social media news outlets for public awareness, including the list of sex offenders who were representing themselves to the public as Jiu-Jitsu coaches.

2) A Case Study on what Bullshido was, and why open access, community driven consumer and protection websites could be valuable to Law Enforcement, Government Agencies, and to University Researchers who did work in the areas of consumer abuses. This case study would be:

- Published in an Academic Journal, and to various Criminal Justice related listserver boards used by LE, Government Agencies, University Cyber Forensic departments, and Cyber Forensic industry consultants.

3) A Teaching Discussion Case that would document what we did and why, that would be used within Cyber Forensic classrooms. These cases were usually assigned as reading to provoke class discussions, and often ended up being used as textbook chapters or supplementary materials.

Murphy also recruited a professional sports reporter who had worked for traditional newspapers who would give the journalistic perspective as requested, and she would likely run a story for traditional newspaper publication after the project was completed.

If the project and its process proved successful, Murphy and his team would then also repeat the process: Judo coaches, then Tae Kwon Do coaches, and so forth down the list of different martial arts styles.

\section{The Decision}

So far, Murphy had developed a list of several thousand people representing themselves to be Brazilian Jiu-Jitsu or Gracie Jiu-Jitsu Black Belts in the United States.

A trial run of running the names through the National Sex Offender Registry manually produced a huge number of false positives.

Further, the university where Murphy worked might not want their name or the names of the university students associated with the project because it was by definition dealing with a criminal population, trained to skillfully commit violence--who may seek retribution for the study being done.

The organizations the Black Belts belong to also may not appreciate the study being done, and were well funded large organizations that expressed their displeasure in any number of ways, ranging from throwing Murphy out of the organizations to providing legal and/or social pressure on Murphy to suppress the study or recant any results.

Finally, Murphy received multiple death threats when he released the petition against children under the age of 12 being put in for profit submission matches without early referee intervention on submissions.

Murphy had to make some decisions:

1) Should he put his university's name on the study or would this expose his university to visits from unsavory characters looking for retribution?

2) Should he allow university students to be co-authors or would this expose them to possible harassment? 
3) Should he proceed to develop automated ways to run sex offender and other criminal background checks across the list of black belts?

4) How should he handle ruling out false positives?

5) Should he give the names of coaches exposed as being sex offenders directly to law enforcement? Should he also give them to Ms. Oden for her to aggressively expose them on social media?

\section{Acknowledgements}

This case study is based upon work supported by the National Science Foundation under Grant No. 1418711.

\section{References}

Bullshido. (n.d.). Retrieved from http://www.bullshido.net/promoted-convicted-sex-criminal-paulsaucido-black-belt/

Gill, T. G., \& Bhattacherjee, A. (2009). Informing science at a crossroads: The role of the client. In T. G. Gill \& E. Cohen (Eds.), Foundations of Informing Science: 1999-2008 (pp. 21-55). Santa Rosa, CA: Informing Science Press.

Gracie Jiu-Jitsu Academy. (n.d.). Retrieved from http://www.gracieacademy.com/

Huber, M., Mulazzani, M., Leithner, M., Schrittwieser, S., Wondracek, G., \& Weippl, E. (2011, December). Social snapshots: Digital forensics for online social networks. In Proceedings of the 27th annual computer security applications conference (pp. 113-122). ACM.

Murphy Jr, W. F. (2011). The Informing Science Institute: The informing system of a transdiscipline. Informing Science: the International Journal of an Emerging Transdiscipline, 14, 91-123.

Murphy, W. (2015, October 6). How to spot con men, criminals, and cult leaders in BJJ. Jiu-Jitsu Times. Retrieved from https://www.jiujitsutimes.com/how-to-spot-con-men-criminals-and-cult-leadersin-bjj/

Sans Institute InfoSec Reading Room. (2014, December 1). Evidence collection from social media sites. Hubert, $\mathrm{K}$.

UFC. (n.d.). Retrieved from http://www.ufc.com/discover/ufc).

US-CERT. (2008). Computer forensics. United States Computer Readiness Team. Retrieved from https://www.us-cert.gov/sites/default/files/publications/forensics.pdf

\section{Biography}

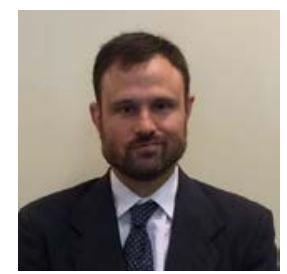

William F. Murphy, Ph.D. has a Ph.D. in Information Systems from the University of South Florida, a Masters in Risk Management from Florida State University, a Masters of Applied Economics from the University of Central Florida, and is completing a post-doctoral Masters in Cyber Security with a concentration in Cyber Forensics at the University of South Florida. 


\section{Exhibit 1: Membership in the Bullshido Community}

\section{By Country:}

Geographic

United States
United Kingdom
Canada
Australia
Germany
Greece
Brazil
Netherlands
Finland
Argentina

$4.4 \mathrm{~K}$
599
384
134
66
64
60

GLoBAL CITIES
St Louis, MO (US)
Athens (GR)
Chicago, IL (US)
Los Angeles, CA (US)
Cheyenne, WY (US)
New York, NY (US)
Houston, TX (US)
Brooklyn, NY (US)
Toronto (CA)

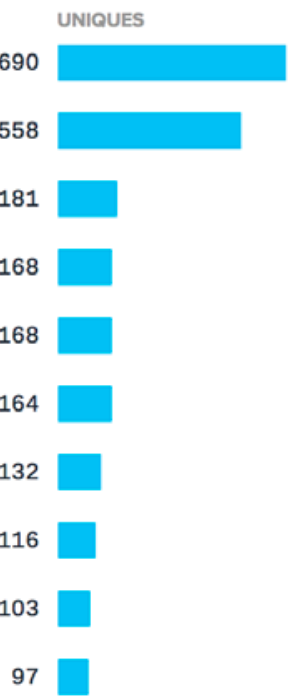

\section{By Occupation:}

Business \& Occupation

Industry \& Occupation

\begin{tabular}{lrll} 
EMPLOYER'S INDUSTRY & \multicolumn{1}{c}{ AFFINITY } & OCCUPATION \\
Active Military & $13.50 \times$ & Scientists \\
Telecom & $3.02 \times$ & Construction \\
Financials \& Banking & $2.57 \times$ & Criminal Justice \\
Non-Profit & $2.36 \times$ & Government \\
Government \& Public Sector & $2.22 \times$ & & Legal
\end{tabular}

$54 x$

$8.95 x$

$7.38 x$

$6.44 x$

$5.59 x$ 


\section{By Education Level:}

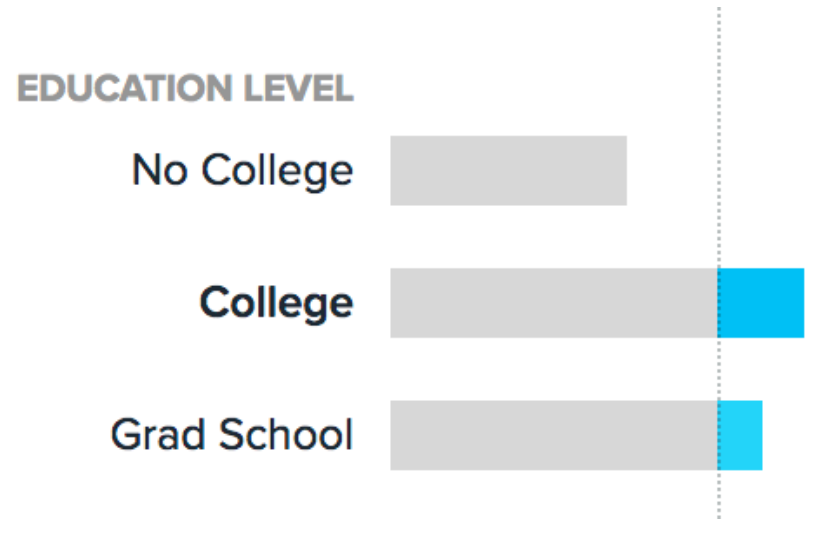

Source: Bullshido.net website 


\section{Exhibit 2: Investigation of Paul Saucido}

\section{Who Promoted Convicted Sex Criminal Paul Saucido to Black Belt?}

by Phrost | April 6, 2017 14:40

The black belt is a symbol of mastery. Should it be a symbol of character too?

In 2009, at a party, Paul Saucido sexually assaulted a woman who was passed out in a bathroom. He then followed her home and assaulted her again, according to the arrest statement. He plead guilty to avoid felony charges and was given four years probation with fourteen years on the sex offender registry:

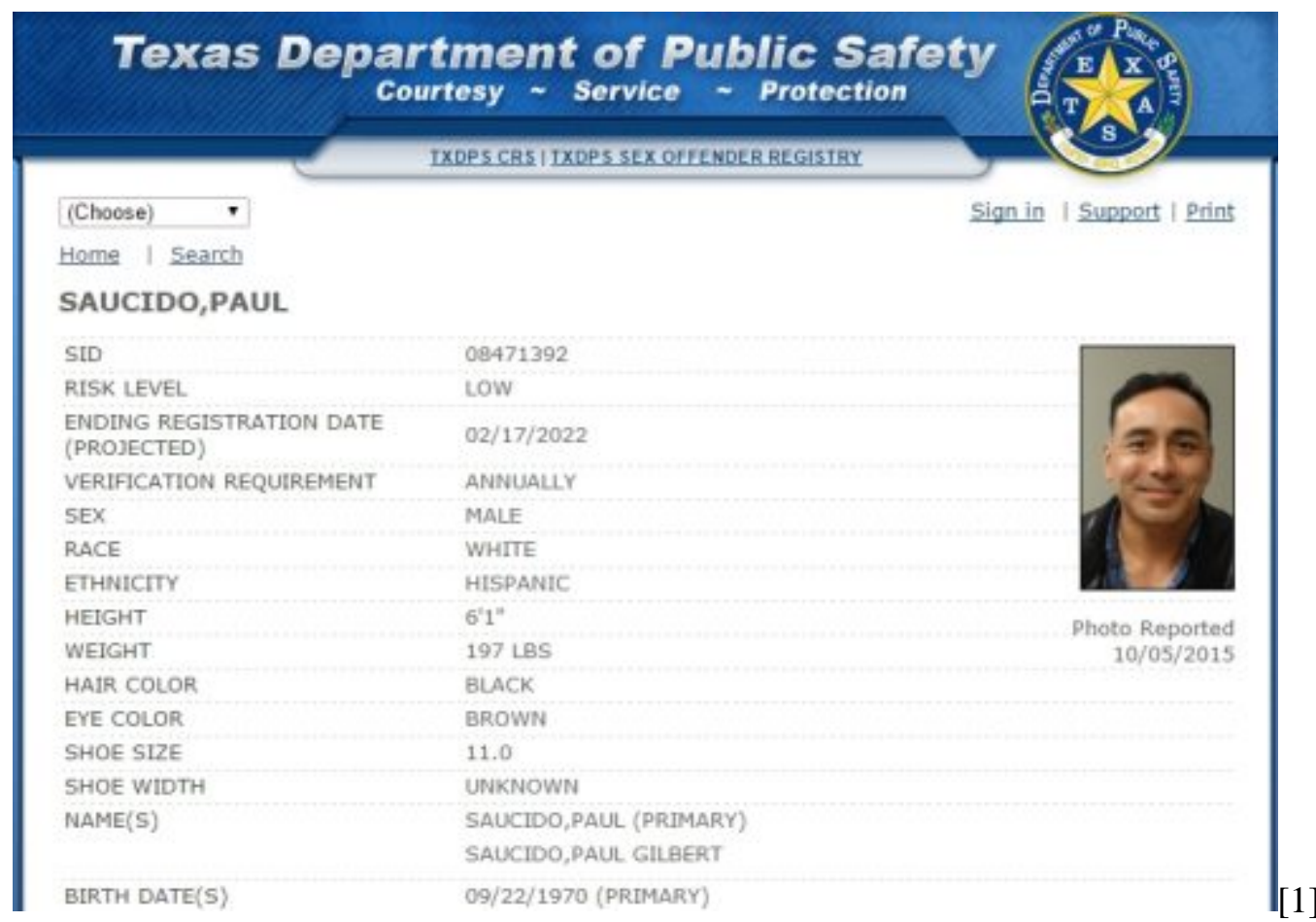

\section{Source:}

https://records.txdps.state.tx.us/SexOffender/PublicSite/Application/Search/Individual.aspx?IND IDN=1 $\underline{2321661}$

"The woman drank too much, an arrest affidavit says, and blacked out in the bathroom after getting sick. She awoke in the bathroom to find Saucido raping her, she told police, and she screamed in pain before blacking out again...

... (The friend) knocked on the bathroom door, as it was believed that (the woman) was inside. After a moment ... (the friend) heard the bathroom door open and saw Saucido look out, then close and lock the door again," the affidavit says. "Once Saucido opened the door, (the friend) saw (the woman) was in there with him. (The friend) said Saucido carried (the woman) to the taxi."... 
...Half an hour later, the friend and boyfriend heard noises coming from the living room, the affidavit says. The boyfriend went to investigate and found Saucido again having sex with the woman, who was still passed out face down on the couch, the affidavit says....

...On police request, the victim agreed to a recorded phone call to Saucido, during which she asked him about the assault, the affidavit says. The papers say Saucido told her during the call that while the incident was happening, he thought to himself, "I don't know what ... I'm doing. I need to sober up."

Saucido, a local celebrity in Austin, Texas, until very recently taught Brazilian Jiujitsu at Austin Zen Fit. Public pressure over the recent revelations of his criminal record [2] seem to have resulted in him no longer working there. And until he resurfaces to teach women at some other unsuspecting school, the question becomes about the credentials he'd use to get the job.

Unlike other professions, a Martial Arts Instructor has no formal requirements for opening or teaching at a school. There's no license required beyond those standard for doing routine business. There's no accrediting body or commission. There's only the belt rank - publicly understood as the most important qualifier of someone's skills to both perform and teach the style for which the belt was awarded.

\section{PAUL SAUCIDO}

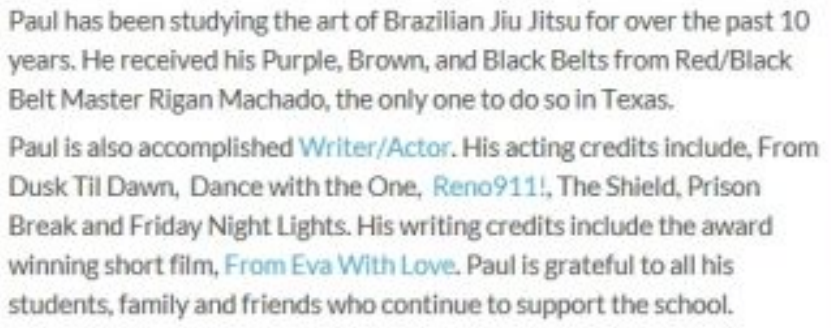

Paul has been studying the art of Brazilian Jiu Jitsu for over the past 10 years. He received his Purple, Brown, and Black Belts from Red/Black Belt Master Rigan Machado, the only one to do so in Texas.

Paul is also accomplished Writer/Actor. His acting credits include, From Dusk Til Dawn, Dance with the One, Reno911!, The Shield, Prison Break and Friday Night Lights. His writing credits include the award winning short film, From Eva With Love. Paul is grateful to all his students, family and friends who continue to support the school.

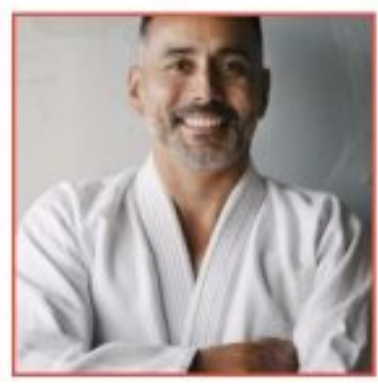

Source: Screenshot from Austin Zen Fit's instructor bio page prior to removal, claiming Saucido received his black belt from Rigan Machado 
Previous belt ranks were granted to Saucido by 8th degree black belt Rigan Machado, considered a legend by many in the Brazilian Jiujitsu world. In 2013, once word of Saucido's conviction became known, Machado disavowed all connections with him:

\section{Rigan Machado}

June $29,2013 \cdot 48$

I just want to make the public aware that I no longer have any relationship or ties to Paul Saucido and Zen Jiu-Jitsu. Zen Jiu-Jitsu is no longer affiliated with me after the information about his sex offender status was made known to me. I have cancelled all seminars present and future with Zen Jiu-Jitsu. I do not support sex offenders and will take all necessary precautions to ensure our mats are safe and students worldwide can train in a safe environment. Background checks will be mandatory for all instructors and staff at any academy that I teach at.

Respectfully, Rigan Machado

Unlike Comment Share $\backsim 290$ Q 36 \& 16

1 You, Alvis Solis, Lindsay Thompson- Machado, Phillip Lietz and 286 others like this.

June 2013 - Machado disavows Saucido

And yet, in 2014 they're posing for selfies together:

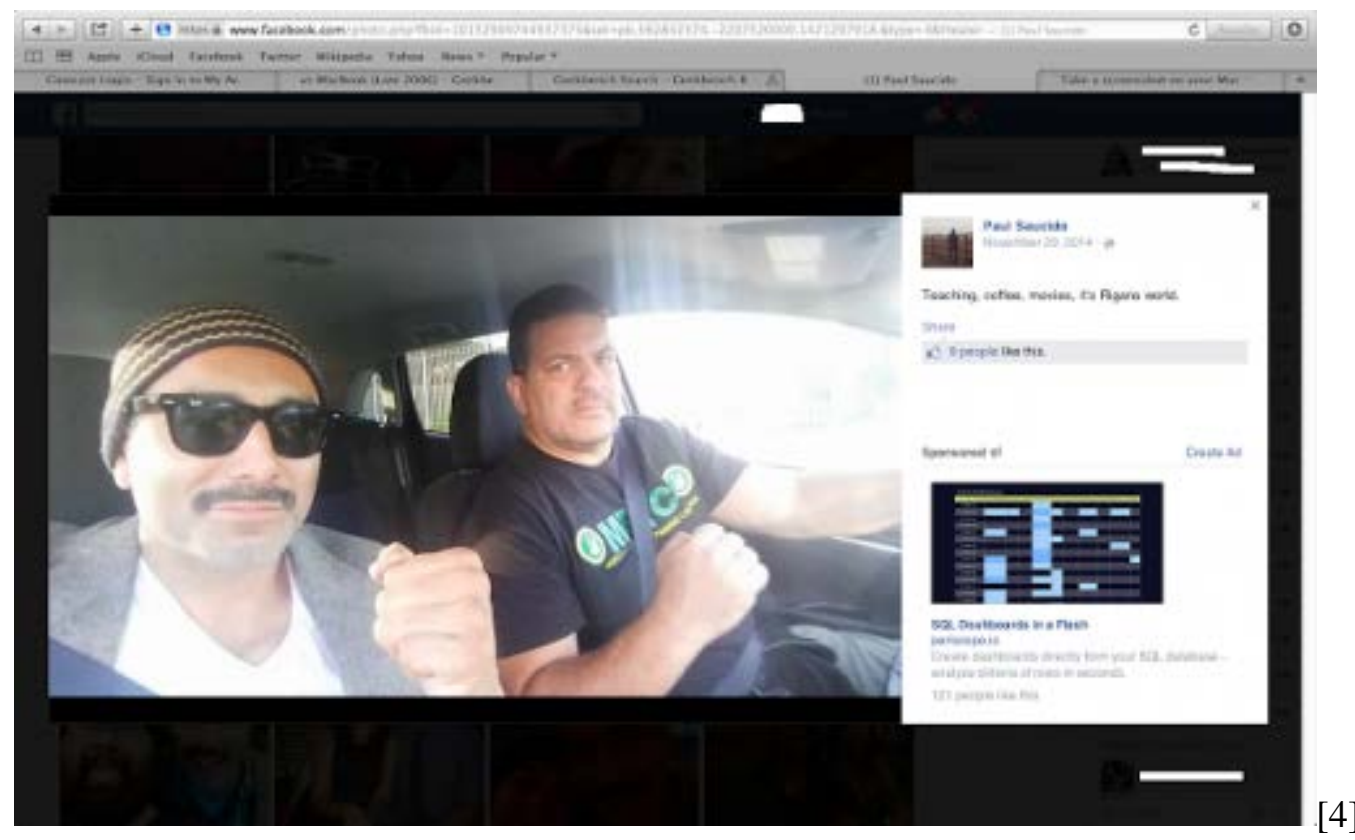


And then, Saucido wearing a black belt, having “gotten his butt kicked” by Rigan:
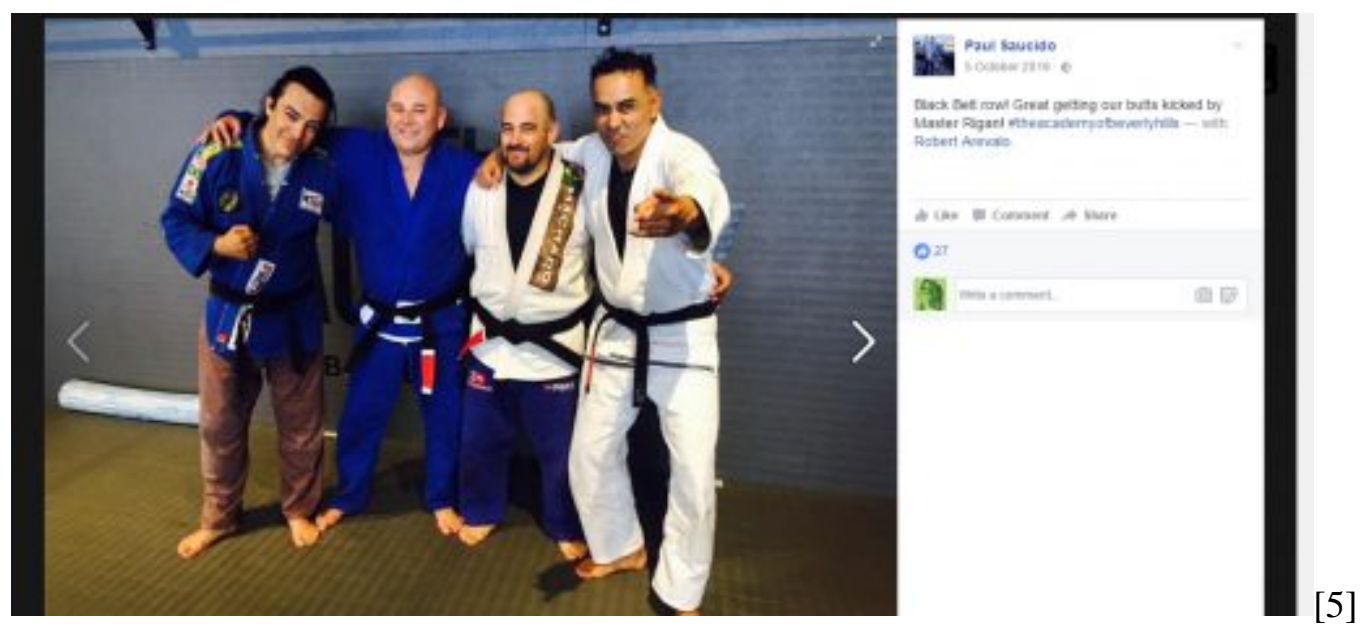

It won't need to be explained to people who do martial arts, but for the sake of those who follow Bullshido for our work on other subjects such as fitness, health, and science; we'll point out that it's extremely unlikely for a practitioner of a style to be promoted up to the rank before black belt and then switch lineages to obtain the next rank, only to maintain the association with his former instructor and lineage.

This is from 2016:

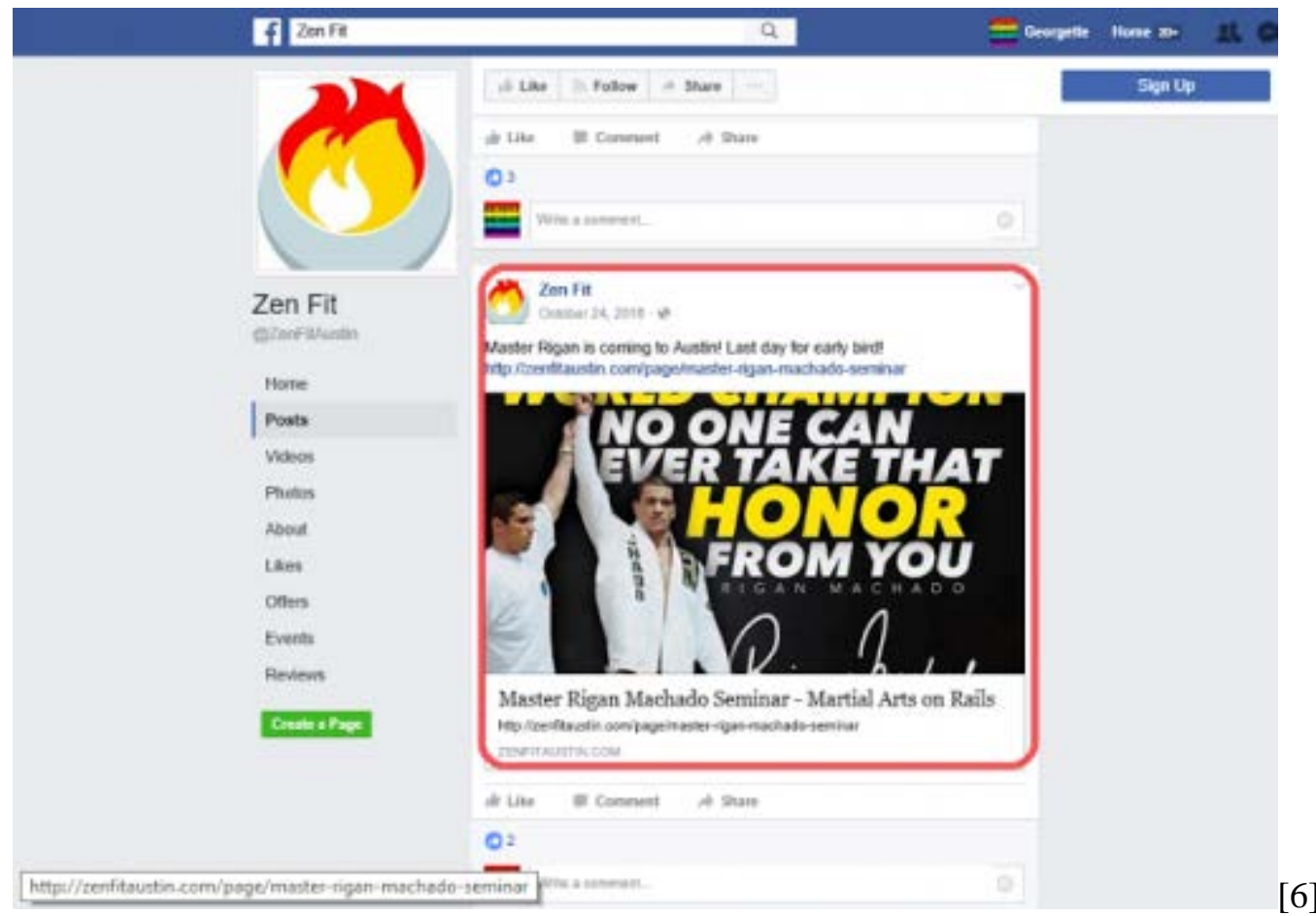


So, the questions remain: If Rigan Machado did not grant convicted sex offender Paul Saucido a black belt, who did? And in a broader sense, does credentialing someone as a black belt in your system endorse that person's character, or simply their skills?

Do instructors who earn their living teaching students the skills to fight off criminals and predators, have any responsibility to protect the community at large from predators in their own ranks?

\section{Endnotes:}

1. [Image]: http://www.bullshido.net/wp-content/uploads/2017/04/paul-saucido-registry.jpg

2. Recent revelations of his criminal record: http://www.bullshido.net/forums/showthread.php?t=126535

3. [Image]: http://www.bullshido.net/promoted-convicted-sex-criminal-paul-saucido-zenfit-austinblack-belt/saucido-rigan/

4. [Image]: http://www.bullshido.net/promoted-convicted-sex-criminal-paul-saucido-zenfit-austinblack-belt/saucido-rigan1/

5. [Image]: http://www.bullshido.net/promoted-convicted-sex-criminal-paul-saucido-zenfit-austinblack-belt/saucido-rigan2/

6. [Image]: http://www.bullshido.net/promoted-convicted-sex-criminal-paul-saucido-zenfit-austinblack-belt/saucido-rigan3/

Source URL: http://www.bullshido.net/promoted-convicted-sex-criminal-paul-saucido-black-belt/

Reprinted with permission by the owner-operators of Bullshido.net and Georgette Oden, head of BJJ investigations 